\title{
Response to "Vulnerability and resistance in the United Kingdom's smart meter transition"
}

\author{
David Shipworth ${ }^{1}$, Michael J. Fell ${ }^{* 1}$, Simon Elam ${ }^{1}$ \\ ${ }^{1}$ UCL Energy Institute, Central House, 14 Upper Woburn Place, London WC1H 0NN, UK. \\ ${ }^{*}$ Corresponding author. UCL Energy Institute, Central House, 14 Upper Woburn Place, London WC1H \\ 0NN, UK. Email: michael.fell@ucl.ac.uk. \\ Word length (excluding abstract, tables, references): 1878 words
}

\section{$\underline{\text { Abstract }}$}

Sovacool et al. (2017) consider and critique the Smart Metering Implementation Programme (SMIP) in the United Kingdom. In this response we highlight a number of areas where we believe it would have been helpful for readers to see additional information. These relate to three areas: how the authors reported on the methods used in their study; how the Programme is addressing technical challenges; and how the Programme is engaging with people in vulnerable situations. We also point out areas where we see emerging challenges, such as engaging non-traditional stakeholders, and how organizations which want to use smart meter data in the public interest might encounter barriers in meeting the demands of the Smart Energy Code. 
$\underline{\text { Introduction }}$

In a recent paper published in Energy Policy, Sovacool et al. (2017) consider and critique the Smart Metering Implementation Programme (SMIP) in the United Kingdom. This is done through a review and analysis of existing literature and transcripts of a number of events. We believe in the importance of scrutinizing major public policy programmes, and that academics have a responsibility to conduct such research. We agree that many of the issues highlighted in this article, such as environmental impact, protection of vulnerable consumers, and consumer engagement with the SMIP are crucial for those leading the SMIP to continue to consider. Nevertheless, in our opinion, in some of the areas touched on by Sovacool et al., more up-to-date or additional contextual information is available than that which is referred to in the article which we feel it is important for readers to consider before drawing conclusions about the challenges faced. In this reponse we aim to round out the picture by highlighting this additional information, and then reorienting the discussion onto what we view as the current challenges and opportunities presented by the SMIP. First, however, we briefly discuss the paper's use of the systematic review method.

\section{$\underline{\text { Research method }}$}

We are supportive of the increased use of systematic review approaches in energy research, since this can help summarize the best available evidence objectively, transparently and comprehensively. Rigorous guidance exists on how they should be conducted and reported (such as through the PRISMA statement and checklist [Liberati et al., 2009]). Importing these expectations to the field of energy is not straightforward or necessarily desirable for reasons we do not have space to rehearse (see Sorrell, 2007; Warren, 2014). However, there are two areas where we would suggest that Sovacool et al. (2017) could have added strength to their review. Firstly through the use of grey (non-peer-reviewed) literature, and secondly through more detailed reporting on the conduct of the review.

Sovacool et al. (2017) outline in some detail their search strategy for academic literature, but add to this only 'a supplemental collection of relevant government reports and media news articles' (p768) with no further detail on identification or extraction. Such an approach risks missing important relevant information. For example, the energy savings factored into the business case for the smart meter rollout 
do, in fact, already lie within the 1-3\% range (for electricity) proposed by the authors (see BEIS, 2016, p20) and have been consistently within this range since the consultation stage impact assessment in 2010 (DECC, 2010, p28). Much of the additional contextual information introduced in the remainder of our response is similarly drawn from policy documents and other grey literature sources. Our main motivation in making this point is to highlight the particular importance of the grey literarature in an applied and policy-relevant domain such as energy. Systematically identifying evidence from grey sources can be challenging (Mahood et al., 2014), but as a research field it is particularly important if our reviews are to provide a useful picture of the available information.

In general it would also have been useful if more information could have been reported about the conduct of the review. This might include, for example, whether quality of evidence was assessed (and if so how), and how information was extracted and analysed. (It would likewise have been helpful to see similar additional information about the analysis of the live events, such as how the particular sample of events was selected, and how the data were analysed.) Where standard stages of any method are omitted, for example due to resource constraints, it is also informative to note these as limitations so that the reader can bear this in mind. (For the standard stages of review methods see Grant and Booth (2009)). This is especially applicable, as is the case here, where there is heavy reliance on press articles (in this context often used for their content, rather than as an indicator of opinion). If the authors were able to share additional information on these points and comment on their significance, we believe this would add useful value to the paper.

The review presented in Sovacool et al. (2017) could possibly have been framed as a content analysis (Krippendorff, 2004) or a systematic map (Grant and Booth, 2009). That is, it is mainly used to analyse how academic attention in this area has been directed (i.e. the object of the study is academic research in the field), rather than focusing on the substantive topic (the SMIP) of which they only provide a partial view. For example, the findings of the review are drawn on to inform Table 2 (Sovacool et al., 2017: p771) listing 47 short- and long-term benefits of smart meters mentioned in the papers, and to highlight that only 28 mention challenges (and all the papers mention challenges that are 'technical' in nature) (p772). This overview of the academic research leads the authors to point out the lack of interest or 
even elements of resistance we uncovered in our systematic review' (p777). These are useful findings in understanding how academic researchers have addressed and portrayed the SMIP. The analysis of live events serves a similar purpose, albeit for a wider range of stakeholders. However, the aims and conclusions of the paper go beyond the question of how SMIP is researched and discussed by academic (and other) observers. Because the systematic search did not lead to comprehensive coverage, and was not accompanied by assessment of evidence quality, it is harder to demonstrate the usefulness of the method employed in speaking to these wider conclusions.

\section{Additional contextual information}

The original acrticle presents a number of technical challenges or issues that might impede a successful rollout of the SMIP. While noting these issues is justified in an article focusing on barriers, it should also be noted that there are credible solutions in place, or in development, to address many of these issues. For example, the article states that "in Scotland, access to fixed broadband services-a prerequisite of a functioning Smart Meter system-is 69\% in rural areas, and 80\% in urban areas" (p776). A corrigendum (Sovacool et al., 2018) notes that a fixed broadband service is not required but observes that (mobile) "network coverage in rural areas is about the same as broadband coverage". The smart meter system does not use a fixed broadbrand network, but nor does it rely on the mobile network alone (particularly in rural areas) and instead uses a blend of Cellular, Mesh and Long Range Radio communication channels to support effective coverage in dense, urban as well as remote, rural areas. The DCC SM-WAN Assurance Strategy states "connectivity will reach over $99 \%$ of UK premises by the end of 2020" (Taylor, 2016, p5) (as the corrigendum acknowledges).

Other Technical Challenges raised (see Figure 4 in Sovacool et al., 2017) include:

a) Buildings with thick walls. This is being addressed through a mandatory industry change to the SMETS protocol facilitating use of $868 \mathrm{MHz}$ HAN signals that have better wall penetration properties.

b) HAN signal propagation in flats. This is being addressed through development of Multiple Dwelling Unit communication systems solutions through the ALT-HAN programme. 
c) Hacking of smart metering infrastructure. Cybersecurity has been a central concern of the SMIP, and many cyber-security experts have been involved in developing robust processes to prevent "hacking" that are mandatory requirements for any organization interacting with the smart meter system (House of Commons, 2016).

The article also raises justifiable concerns relating to the impact of smart meters on consumers from vulnerable groups, who "... are likely to need more help if they are to obtain the full benefits of smart metering" (p775). This is undoubtedly correct, but readers should also be made aware of existing research or operational measures designed specially to address these issues. The 'energywise' project is a $£ 5.5$ million project that commenced in January 2014 specifically to investigate issues of the impact of smart metering on vulnerable and fuel poor households. A recent report on the first stage of the project found electricity savings of $3.3 \%$ on average amongst participants receiving a smart meter with in-home display along with energy efficiency advice and devices (UKPN, 2017). The Smart Metering Installation Code of Practice_(SMICoP, 2013) also addresses some of these concerns, and the Citizens Advice report cited shows that 18 key safeguards to assist vulnerable customers with the smart meter rollout were offered by $90 \%$ of suppliers surveyed ( 11 of which were offered by all suppliers). Smart Energy GB, the organization responsible for public engagement with the smart meter roll-out, has partnered with groups such as Age UK, National Energy Action and the National Housing Federation to help better support relevant socio-demographic groups (in addition to the partnerships with Citizens Advice, Centre for Sustainable Energy and Scottish \& Southern Energy mentioned in the conclusion of the original article).

\section{Emerging challenges}

While the original article addresses possible problems currently associated with the SMIP, we believe that there are other less acknowledged challenges that should also be on the agenda for consideration. One of these will be better integrating the concerns and interests of a wider range of stakeholders into the SMIP - such as new suppliers, technology companies, consumer access device (CAD) manufacturers, research organizations, and others - who will participate in the evolution of the UK's energy system over the coming years. In particular, there is likely to be a tension between measures 
intended (rightly) to protect privacy and security of smart meter data, and the potential to extract maximum value from the roll-out.

In the UK, smart meter data will be accessed by any third party (including energy suppliers) through the Data and Communications Company (DCC). In order to access data, organizations must adhere to the Smart Energy Code (and associated governance documents). Compliance with the Code is likely to be challenging for smaller organizations due to the significant resources required to both engage with and implement its requirements. One specific manifestation of this will be around obtaining and maintaining consent to access and use smart meter data. Incumbent large energy suppliers have existing

infrastructures in place (serving millions of customers) that will allow them to manage this process much more easily than may be the case for other organizations which may (for example) wish to use smart meter data for public benefit. There is a risk that innovative and socially beneficial applications of smart meter data will not be realized unless mechanisms can be found to facilitate access for such organizations while retaining the necessary safeguards relating to data privacy and security. One model of such facilitation is the EPSRC funded Smart Meter Research Portal, which will provide access to smart meter data to accredited researchers from thousands of participants who have provided consent for their data to be used for research purposes.

\section{$\underline{\text { Conclusion }}$}

Sovacool et al. (2017) critique a number of aspects of the UK Smart Meter Implementation Programme. We have presented additional contextual information on technical and vulnerability challenges, and highlighted possible emerging challenges, that we believe will be important for readers to bear in mind in forming a judgment about the approach taken in SMIP and where (if they choose to) they should focus their own critique.We believe it would be useful to receive additional clarity from the authors on the conduct and specific objectives of their original analysis.

\section{$\underline{\text { References }}$}

BEIS, 2016. SMART METER ROLLOUT COST-BENEFIT ANALYSIS Part II - Technical annex.

Department for Business, Energy and Industrial Strategy. 
DECC, 2010. GB-wide smart meter roll out for the domestic sector. Department of Energy and Climate Change, London, UK.

Grant, M.J., Booth, A., 2009. A typology of reviews: an analysis of 14 review types and associated methodologies. Health Inf. Libr. J. 26, 91-108. https://doi.org/10.1111/j.1471-1842.2009.00848.x

House of Commons, 2016. Evidence Check: Smart metering of electricity and gas, Appendix 3: Written evidence submitted by the Government on smart meter security. House of Commons Science and Technology Committee.

Krippendorff, K., 2004. Content Analysis: An Introduction to Its Methodology. Sage.

Liberati, A., Altman, D.G., Tetzlaff, J., Mulrow, C., Gøtzsche, P.C., loannidis, J.P.A., Clarke, M., Devereaux, P.J., Kleijnen, J., Moher, D., 2009. The PRISMA statement for reporting systematic reviews and meta-analyses of studies that evaluate healthcare interventions: explanation and elaboration. BMJ 339, b2700. https://doi.org/10.1136/bmj.b2700

Mahood, Q., Van Eerd, D., Irvin, E., 2014. Searching for grey literature for systematic reviews: challenges and benefits. Res. Synth. Methods 5, 221-234. https://doi.org/10.1002/jrsm.1106 SMICoP, 2013. Smart Metering Installation Code of Practice.

Sorrell, S., 2007. Improving the evidence base for energy policy: The role of systematic reviews. Energy Policy 35, 1858-1871. https://doi.org/10.1016/j.enpol.2006.06.008

Sovacool, B.K., Kivimaa, P., Hielscher, S., Jenkins, K., 2018. Corrigendum to "Vulnerability and resistance in the United Kingdom's smart meter transition" [Energy Policy 109 (2017) 767-781]. Energy Policy 113, 52. https://doi.org/10.1016/j.enpol.2017.10.061

Sovacool, B.K., Kivimaa, P., Hielscher, S., Jenkins, K., 2017. Vulnerability and resistance in the United Kingdom's smart meter transition. Energy Policy 109, 767-781. https://doi.org/10.1016/j.enpol.2017.07.037

Taylor, E., 2016. Smart Meter Wide Area Network DCC Assurance Strategy. Data and Communications Company.

UKPN, 2017. energywise: The Final Energy Saving Trial Report. UK Power Networks, London, UK. Warren, P., 2014. The use of systematic reviews to analyse demand-side management policy. Energy Effic. 7, 417-427. https://doi.org/10.1007/s12053-013-9230-x 


\section{Declaration of interests}

The authors, as researchers working in the field of smart energy, have many and longstanding connections with organizations and programmes referred to in Sovacool et al. (2017).

David Shipworth is a Professor in the UCL Energy Institute. He has a long-standing involvement with the Smart Metering Implementation Programme. He is the UK Government's Industry and Academic representative to International Energy Agency's Demand Side Management Technology Collaboration Programme. He has been a consultant and advisor to the UK government and industry on smart metering over the last ten years having done work for BEIS; SEGB; ETI; ESC; EdF; E.ON; SSE; and UKPN. He is academic lead on the 'Vulnerable Customers and Energy Efficiency project (Energywise)' (UKPNT205). A 4-year grant from Jan 2014 to Dec 2017 funded by the Ofgem Low Carbon Network Fund and lead by UK Power Networks with British Gas; CAG Consultants; Tower Hamlet Homes; Polar HARCA; National Energy Action, Element Energy and Institute for Sustainability. Value $\_5.5 \mathrm{M}$. He is a Co-Investigator on the RCUK 'Centre for Energy Epidemiology (CEE): the study of energy demand in a population'. 6-year grant from Apr 2013 to Mar 2018. Value: £6M. He is a Co-Investigator on the RCUK 'Smart Meter Research Portal' project (EP/P032761/1). A five year £6M pound project from Aug 2017 to Aug 2022. He is a Co-Investigator on the 'Data-Driven Methods for a New National Household Energy Survey' (BIG-small) project (EP/M008223/1). A 3-year grant from Jan 2015 to Dec 2017. Value $£ 600 \mathrm{~K}$.

Dr Michael Fell is a Research Associate in the UCL Energy Institute. His research has focused on flexibility in consumer electricity demand, which smart meters are widely viewed as having an important role in facilitating. He has worked on projects funded by three of the organizations mentioned in the original paper: Smart Energy GB (on consumer uptake of demand response, and on the use of smart meter data in health and care applications); Citizens Advice (on the value of time of use tariffs in GB); and BEIS (a policy evaluation scoping exercise unrelated to smart metering). He has also worked on secondment in the open science team in BEIS, where his work was not connected with smart metering. 
Simon Elam is a Principal Research Fellow at UCL Energy Institute with several research interests relating to smart meters. He is the Director of the RCUK Smart Meter Research Portal project (EP/P032761/1). The Engineering and Physical Sciences Research Council provided £6m of funding for a 5-year project (Aug. 2017-2022) to develop a Smart Meter Research Portal (SMRP) which will provide vital access to energy data for the UK research community. The SMRP consortium comprises 7 universities and the Energy Saving Trust. He led research streams investigating energy saving in response to smart meters (and IHDs) on the 'Vulnerable Customers and Energy Efficiency project (Energywise)' (UKPNT205), funded by the Ofgem Low Carbon Network Fund and lead by UK Power Networks with British Gas; CAG Consultants; Tower Hamlet Homes; Polar HARCA; National Energy Action, Element Energy and Institute for Sustainability. Value $£ 5.5 \mathrm{M}$. He is the author of a Teddinetfunded report "Smart Meter Data and Public Interest Issues - The National Perspective" 